\title{
Insufficient spring irrigation increases abnormal splitting of pistachio nuts
}

\begin{abstract}
Mark A. Doster 」 Themis J. Michailides 」 David A. Goldhamer David P. Morgan
\end{abstract}

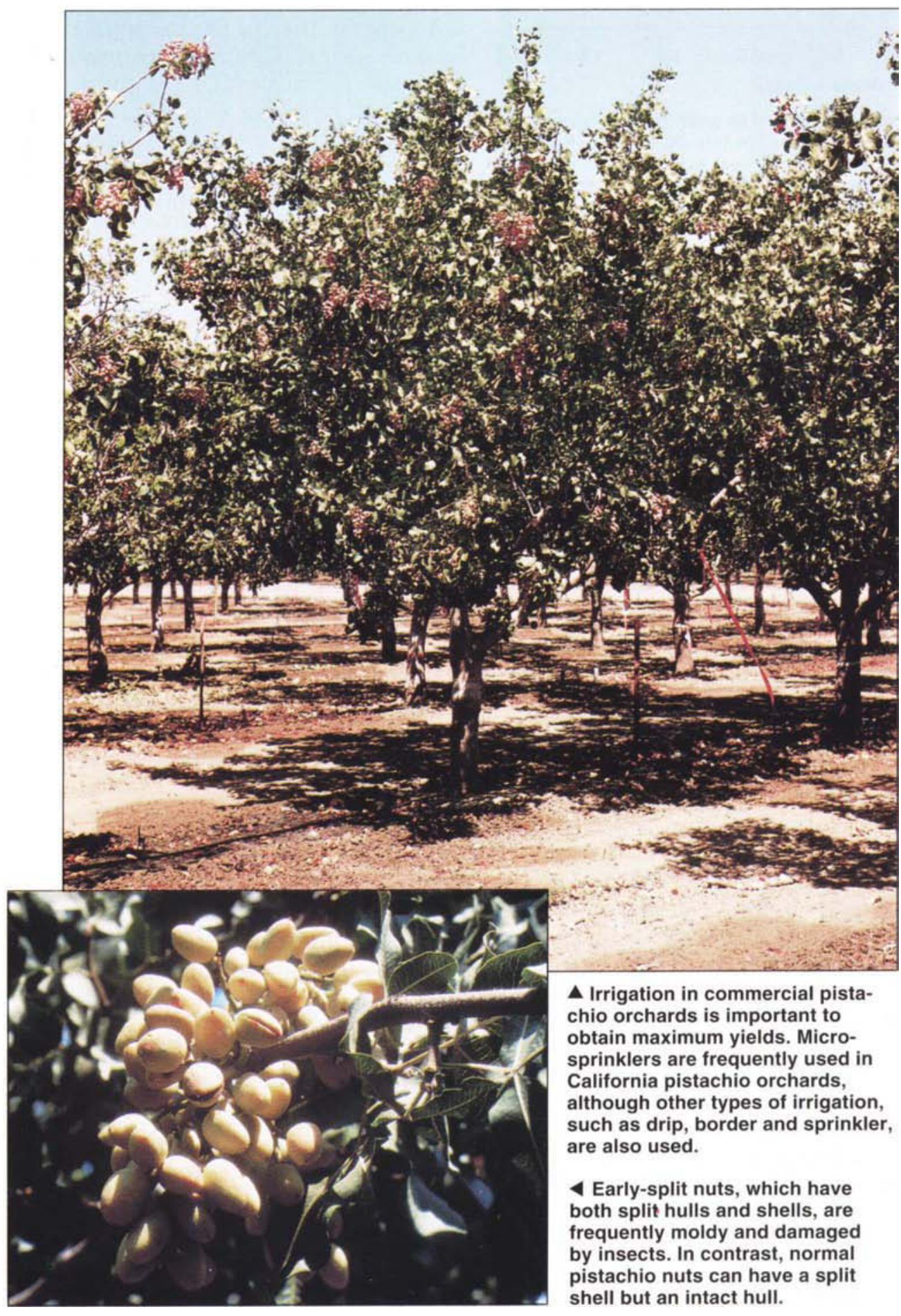

Abnormal pistachio nuts, known as "early-split nuts," have both the hull and shell split while still on the tree, exposing the kernel to invasion by insects and molds. Deficit irrigation of pistachio trees in April and May resulted in substantial increases in the formation of early-split nuts in late summer, while extreme deficit irrigation in July and August resulted in decreased formation. However, deficit irrigation during the period of shell hardening, mainly in June, did not affect early-split formation.

\section{Distachio trees (Pistacia vera) are 1 drought tolerant and can survive} with very little water. For maximum yields, however, substantial amounts of water must be supplied during the growing season. In the San Joaquin Valley, the total evapotranspiration (combination of soil evaporation and plant transpiration, representing total water use of the crop) for the pistachio growing season is about 42 inches, and the maximum evapotranspiration rate during midsummer is about 0.32 inches per day (Goldhamer et al. 1985). To deliver the needed water to the pistachio trees, drip and microsprinkler irrigation are used on about $90 \%$ of the pistachio acreage in California, and border and sprinkler systems on the remaining acreage.

In the orchard, pistachio nuts typically split their shells, which are surrounded by a hull. Most nuts, however, do not split their surrounding hull and have an intact hull until after harvest. This distinguishes pistachio nuts from almonds and walnuts, which frequently rupture their hulls in the orchard but typically not the shells. Unfortunately, a small percentage of atypical pistachio nuts, known as "early-split nuts," rupture both their hulls and shells in the orchard, exposing the kernel to invasion by fungi and insects. An additional problem is that the rupture of the hull usually results in dark staining of the shell.

Many ripening fruits, including apples, cherries, citrus, grapes, prunes 
and tomatoes, can crack or split prior to harvest. Similarly, the hulls of pistachio nuts sometimes crack while still on the tree. This cracking, however, is distinct from the hull-splitting of early-split nuts, and can be distinguished by the location of the cracking. For early-split nuts, the hull splits only when the shell splits, and the split is always along the shell suture or split, whereas hull-cracking occurs elsewhere and sometimes occurs when the shell has not split. Another difference is that hull-cracking of pistachio nuts only occurs very close to harvest time, which is why these nuts usually do not have much fungal decay or insect infestation.

The hulls of early-split nuts rupture throughout a period starting in late July and continuing through to harvest, typically in September. This long period allows the kernels of some early-split nuts to be decayed by molds and infested with the insect navel orangeworm (Amyelois transitella), an important pest of pistachio nuts. Because of the problems associated with early-split nuts, we investigated the role of irrigation on their formation.

\section{Orchard survey}

Commercial pistachio orchards were surveyed at harvest from 1991 to 1993 to determine typical incidences of early-split nuts. In these surveys and in all experiments, the common cultivar 'Kerman' was used. Nine or 10 orchards located in Fresno, Kern and Madera counties were surveyed in each year. In each orchard, more than 2,000 nuts on the trees were examined for early-split nuts at harvest time. Various types of irrigation were represented; depending on the year, between three and five orchards used microsprinklers, two or three used border and three used sprinklers.

Typically, very few pistachio nuts became early-split nuts (the mean incidence of early-split nuts ranged from $2.3 \%$ to $3.3 \%$, depending on the year), although every orchard had some early-split nuts (table 1). In only one instance (an orchard in 1992) was the incidence of early-split nuts less than $0.5 \%$, and only twice (one orchard in 1992 and another in 1993) was the inci- dence greater than $5.0 \%$. In general, the type of irrigation used had little effect on the formation of early-split nuts. For example, in 1991 the mean percentage of nuts that were earlysplit was $2.8 \%, 2.6 \%$ and $2.1 \%$ for orchards that were irrigated with microsprinklers, flood and sprinklers, respectively. Even though the incidence of early-split nuts is typically low, early-split nuts represent a serious problem for processors. The earlysplit nuts are the major source of nuts with decayed and insect-infested kernels, but they are difficult to remove because the shells cover the kernels and make detecting nuts with poor quality kernels difficult.

\section{Timing of deficit irrigation}

The period during the growing season when deficit irrigation occurred determined whether the formation of early-split nuts increased, decreased or remained about the same compared to irrigating to full or near-full crop evapotranspiration (tables 2 through 5). Evapotranspiration was calculated using reference crop water-use values from a nearby California Irrigation Management Information System (CIMIS) weather station and crop coefficients previously determined for mature pistachio trees. In an experiment in 1992, 10 irrigation treatments were applied in a commercial orchard of mature pistachio trees in Kings County. The treatments consisted of irrigation by microsprinklers at various percentages of the crop evapotranspiration for certain periods during the development of the nuts. The amounts of water for the deficit irrigation treatments were applied by using different combinations of microsprinkler sizes and system operating pressures. For each of the six replications, approximately 1,000 nuts on a tree were examined on Aug. 25 for early-split nuts.

Even though this experiment had 10 treatments, only the most extreme treatments are presented in table 2. Deficit irrigation through mid-May (treatment A) substantially increased early-split formation compared to all other treatments, while deficit irrigation from early July to harvest (treatment D) decreased early-split forma- tion (table 2). However, deficit irrigation during the period of mid-May to early July (treatment B) only slightly increased (not statistically significant) early-split formation compared to the control (treatment $\mathrm{C}$ ).

The development of pistachio nuts during the growing season is complex. Three distinct stages have been identified (Crane et al. 1971). During the first stage, which starts with bloom and lasts until about mid-May, the developing shell increases in size until it reaches almost the final size. During the second stage, which lasts from mid-May to about mid-June, the nut has little growth but the shell becomes lignified and hard. Finally, during the third stage, which lasts from late June to harvest, the kernel expands and finally the shell splits. An important part of the last stage is the separation of the hull from the shell. The hullsplitting of early-split nuts, which probably results when the shell splits before the hull is sufficiently separated from the shell, occurs during the second half of the third developmental stage, starting in late July and continuing until harvest (Doster and Michailides 1995).

The splitting of the hull that is characteristic of early-split nuts is strongly affected by deficit irrigation during late spring, especially during the period of shell growth (tables 2 and 3 ). For example, trees that were deficitirrigated during the first stage of nut development (treatment $A$ ) in the Kings County experiment had only about 4 inches less water applied than the control (treatment $C$ ) but had over three times the incidence of early-split nuts, whereas trees that were deficitirrigated during the third stage (treatment D) had a much larger difference

\begin{tabular}{|c|c|c|c|c|}
\hline \multirow[b]{3}{*}{ Year } & \multirow{3}{*}{$\begin{array}{l}\text { Number of } \\
\text { orchards } \\
\text { surveyed }\end{array}$} & \multirow{2}{*}{\multicolumn{3}{|c|}{$\begin{array}{l}\text { Early-split nuts } \\
\text { Among orchards }\end{array}$}} \\
\hline & & & & \\
\hline & & Mean & Min. & Max. \\
\hline & & \multicolumn{3}{|c|}{ 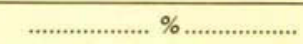 } \\
\hline 1991 & 10 & 2.5 & 1.5 & 3.8 \\
\hline 1992 & 10 & 2.3 & 0.1 & 8.2 \\
\hline 1993 & 9 & 3.3 & 0.8 & 5.8 \\
\hline
\end{tabular}




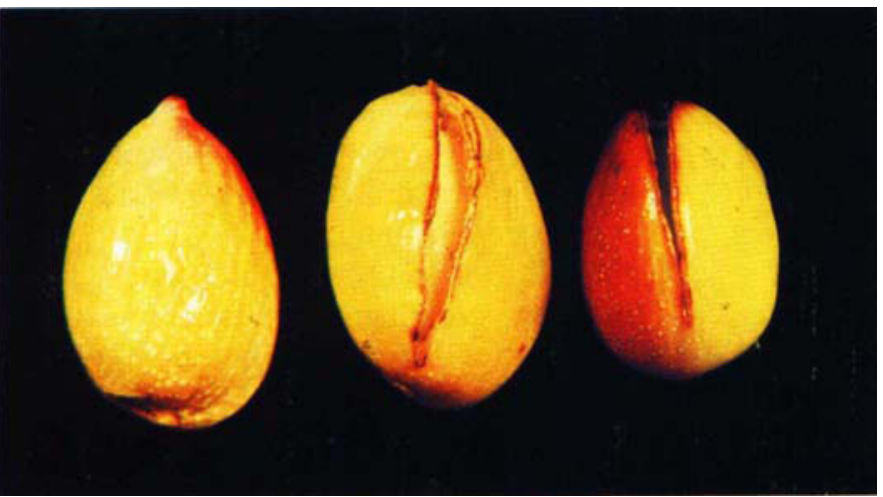

For most pistachio nuts, the hull remains intact until after harvest, left, whereas a small percentage of nuts rupture their hulls either by cracking, middle, or splitting along the shell suture, which is characteristic of early-split nuts, right.

in water applied (about 16 inches less than the control) but only a relatively small difference in the incidence of early-split nuts (table 2 ).

In order to verify the sensitivity of early-split formation to deficit irrigation during late spring, we selected two commercial pistachio orchards in 1993. The growers irrigated the orchards as usual, except that replicated blocks were not irrigated during one of the irrigations in spring. One irrigation was skipped on May 15 in blocks in a flood-irrigated orchard in Tulare County and on May 22 in blocks in a sprinkler-irrigated orchard in San Joaquin County. For both orchards, the number of early-split nuts was counted in 250 nuts on each of 10 trees for each of three blocks in September

1993. For both orchards, the trees that received deficit irrigation during May had substantially more early-split nuts than the other trees (table 3). Growers can easily underestimate the water needs of pistachio trees in spring because of the difficulty of estimating the contribution of soil stored water and rainfall to crop evapotranspiration. Also, as temperatures rise, days lengthen and the trees grow in spring, the crop evapotranspiration can increase rapidly, making it easy for growers to fall behind in their irrigation.

Unfortunately, the relationship between the formation of early-split nuts and normal shell-splitting is not clear. Growers are paid substantially more for pistachio nuts with split shells, so they would like to maximize normal shell-splitting. However, becauşe early-split nuts are frequently moldy, damaged by insects and with discolored shells, growers should try to decrease the number of early-split nuts produced. Orchards with only a few early-split nuts frequently have a relatively low percentage of normal nuts with split shells. For example, in the orchard surveys of 1992 and 1993 the orchard that had the lowest incidence of early-split nuts also had the lowest percentage of normal shell-splitting, possibly due to deficit irrigation in late summer. Furthermore, in the Kings

TABLE 2. Effect of deficit irrigation on incidence of early-split nuts and normal shell-splitting at harvest in a microsprinkler-irrigated orchard in Kings County

\begin{tabular}{|c|c|c|c|c|c|}
\hline \multirow[b]{2}{*}{ Treatment } & \multicolumn{3}{|c|}{ Percentage of crop evapotranspiration applied* } & \multirow[b]{2}{*}{$\begin{array}{c}\text { Early-split } \\
\text { nuts }\end{array}$} & \multirow[b]{2}{*}{$\begin{array}{l}\text { Normal-split } \\
\text { nuts }\end{array}$} \\
\hline & $\begin{array}{l}\text { Stage } 1: \dagger \\
\text { through } \\
\text { May } 15\end{array}$ & $\begin{array}{c}\text { Stage 2: } \\
\text { May 16- } \\
\text { July } 1\end{array}$ & $\begin{array}{c}\text { Stage } 3 \text { : } \\
\text { July } 2 \\
\text { to harvest }\end{array}$ & & \\
\hline & & & & & \\
\hline A & $0(0.5) \ddagger$ & $100(9.1)$ & $100(17.2)$ & $2.77 \mathrm{a} \S$ & $85.0 \mathrm{a}$ \\
\hline B & $100(4.4)$ & $0(0.0)$ & $100(16.2)$ & $1.11 \mathrm{~b}$ & $61.8 \mathrm{c}$ \\
\hline C & $100(4.4)$ & $100(8.6)$ & $100(16.4)$ & $0.80 \mathrm{bc}$ & $73.8 \mathrm{~b}$ \\
\hline D & $100(4.4)$ & $100(8.7)$ & $0(0.0)$ & $0.45 \mathrm{c}$ & $47.8 \mathrm{~d}$ \\
\hline
\end{tabular}

"The percentages represent the level of irrigation that the researchers attempted to apply. Because experiment took place during a drought year, water supplies were restricted and slightly less water was applied than full crop evapotranspiration in some cases.

†Stage 1 corresponds to the period of shell expansion; stage 2 to shell hardening; and stage 3 to kernel growth.

$\ddagger$ Number in parentheses is the actual amount of water applied in inches for the time period.

$\S$ Statistical analysis was performed on arcsine-transformed data. Numbers followed by the same letter are not significantly different $(P=0.05)$ by pairwise comparisons using Fisher's LSD.

County experiment, treatment A (early deficit) had the highest incidence of both early-split nuts and normal shellsplitting, and treatment D (late deficit) had the lowest incidences (table 2). In the other experiments, however, even though the treatments resulted in large differences in incidence of early-split nuts, the treatments differed only slightly in normal shell-splitting (tables 3 and 4). It is not known why early-split formation is sometimes correlated with normal shell-splitting and sometimes not.

\section{Regulated deficit irrigation}

Regulated deficit irrigation is an approach to scheduling the irrigation of orchards so that water is saved with little impact on nut production. Typically, various stages in fruit or nut development are tested for the effect of deficit irrigation on yield and quality. For various crops, including almonds, grapes, olives, peaches, prunes and walnuts, the developmental stage has been proposed during which deficit irrigation has a minimal effect on crop yield.

Various experiments have shown that deficit irrigation during stage 2 of pistachio nut development, which is the period of shell hardening, has the least effect on nut quality and yield. Extreme deficit irrigation during shell hardening (treatment B) in the Kings County experiment did not substantially increase the incidence of early-

TABLE 3. Effect of skipping an irrigation application in May on the incidence of early-split nuts and normal shell-splitting at harvest in two commercial pistachio orchards

\begin{tabular}{|c|c|c|c|}
\hline Orchard & $\begin{array}{l}\text { Irrigation } \\
\text { treatment }\end{array}$ & $\begin{array}{l}\text { Early- N } \\
\text { split } \\
\text { nuts }\end{array}$ & $\begin{array}{l}\text { Normal- } \\
\text { split } \\
\text { nuts }\end{array}$ \\
\hline & & $\ldots \ldots . . . \%$ & $\% \ldots \ldots \ldots . . .$. \\
\hline \multirow{2}{*}{$\begin{array}{l}\text { Sprinkler } \\
\text { irrigated } \\
\text { (San Joaquin } \\
\text { County) }\end{array}$} & $\begin{array}{l}\text { Skip one } \\
\text { application } \\
\text { in May }\end{array}$ & $6.2 \mathrm{a}^{*}$ & $82 \mathrm{NS}$ \\
\hline & Normal grower & $3.9 \mathrm{~b}$ & 79 \\
\hline \multirow{2}{*}{$\begin{array}{l}\text { Flood irrigated } \\
\text { (Tulare County) }\end{array}$} & Skip one & $10.5 \mathrm{a}$ & 76 NS \\
\hline & Normal grower & $5.7 b$ & 73 \\
\hline
\end{tabular}

"Statistical analysis was performed on arcsinetransformed data for each orchard separately. Numbers followed by the same letter are not significantly different $(P=0.05)$ by pairwise comparisons using Fisher's LSD. NS = no significant differences. 
split nuts (table 2). Furthermore, in this same experiment, a treatment that was the same as the control except for irrigating at $50 \%$ crop evapotranspiration during stage 2 (the period from mid-May through early July) actually had a slightly lower incidence of earlysplit nuts (results not shown).

In an experiment investigating regulated deficit irrigation in a commercial microsprinkler-irrigated pistachio orchard in Kern County, earlysplit nuts were counted in 250 nuts on each of 10 trees for each of five blocks on Sept. 20, 1994. Deficit irrigation during stage 2 (treatment RDI-2) made little difference in early-split formation compared to the control, whereas deficit irrigation during both stages 1 and 2 (treatment RDI-1) had a higher incidence of early-split nuts (table 4). Treatments RDI- 1 and RDI- 2 both resulted in mild to moderate water stress (as measured by predawn leaf water potential), but RDI-1 resulted in water stress starting in May, whereas RDI-2 did not result in water stress until June.
In another experiment in a commercial microsprinkler-irrigated pistachio orchard in Madera County, regulated deficit irrigation of $25 \%$ and $50 \%$ of crop evapotranspiration during the period from midMay through late June did not result in increased incidences of early-split nuts in both 1992 and 1993 compared to the control of irrigating at $100 \%$ crop evapotranspiration (table 5), even though mild to moderate water stress occurred in the trees with deficit irrigation (as determined by measuring the predawn leaf water potential).

Regulated deficit irrigation in pistachio orchards done at the correct time - between shell growth and kernel growth - does not seem to affect early-split formation and can save water. Deficit irrigation done earlier in
TABLE 4. Effect of regulated deficit irrigation (RDI) on the incidence of early-split nuts and normal shell-splitting at harvest in a microsprinkler-irrigated orchard in Kern County

\begin{tabular}{|c|c|c|c|c|}
\hline \multirow[b]{2}{*}{ Treatment } & \multicolumn{2}{|c|}{$\begin{array}{c}\text { Percentage of crop } \\
\text { evapotranspiration applied }\end{array}$} & \multirow[b]{2}{*}{ Early-split nuts } & \multirow[b]{2}{*}{$\begin{array}{l}\text { Normal- } \\
\text { split nuts }\end{array}$} \\
\hline & Until May 16 & $\begin{array}{l}\text { May } 17- \\
\text { July } 1\end{array}$ & & \\
\hline & ...................... & .... & 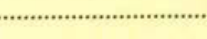 & ..................... \\
\hline RDI-1 & $50(1.1)^{*}$ & $50(3.5)$ & 0.81 at & 47.7 NS \\
\hline RDI-2 & $100(2.2)$ & $50(5.9)$ & $0.37 b$ & 45.8 \\
\hline Control & $100(2.1)$ & $100(12.5)$ & $0.45 b$ & 49.5 \\
\hline
\end{tabular}

-The number in parentheses is the amount of water applied in inches for the time period. Approximately the same amount of water was applied during the rest of the year after July 1 for each treatment (19.3-20.0 inches, depending on treatment), which represented full crop evapotranspiration.

tStatistical analysis was performed on arcsine-transformed data. Numbers followed by the same letter are not significantly different $(P=0.05)$ by pairwise comparisons using Fisher's LSD. NS means no significant differences.

TABLE 5. Effect of regulated deficit irrigation (RDI) on the incidence of early-split nuts in a microsprinkler-irrigated orchard in Madera County

\begin{tabular}{|c|c|c|c|c|}
\hline \multirow[b]{2}{*}{ Treatment } & \multicolumn{2}{|c|}{1992} & \multicolumn{2}{|c|}{1993} \\
\hline & $\begin{array}{l}\text { ETC for May 17- } \\
\text { June } 29^{*}\end{array}$ & $\begin{array}{l}\text { Early-split } \\
\text { nuts }\end{array}$ & $\begin{array}{c}\text { ETC for May 16- } \\
\text { June } 21\end{array}$ & $\begin{array}{l}\text { Early-split } \\
\text { nuts }\end{array}$ \\
\hline & & & & ............... \\
\hline RDI-1 & $25(0.5) \dagger$ & 0.9 NS $\ddagger$ & 25 (1.9) & 1.3 NS \\
\hline RDI-2 & $50(2.7)$ & 0.9 & $50(3.2)$ & 1.3 \\
\hline Control & $100(5.6)$ & 1.2 & $100(6.4)$ & 1.5 \\
\hline
\end{tabular}

"Percentage of crop evapotranspiration that was applied during the specified period. Before and after the period of RDI, full crop evapotranspiration was applied to all treatments. For each treatment in 1992, approximately the same amount of water was applied before May 17 (3.7 inches for all treatments) and after June 29 (14.0-14.7 inches, depending on treatment). Similarly, in 1993 approximately the same amount of water was applied before May 16 (3.7-3.9 inches, depending on treatment) and after June 21 (25.7-28.3 inches).

tThe number in parentheses is the amount of water applied in inches for the time period.

$\ddagger$ Statistical analysis was performed on arcsine-transformed data. NS $=$ no significant differences $(P=0.05)$.
The normal developmental stages of pistachio nuts are stage 1 , the developing shell increases in size, left; stage 2, shell hardens, middle; and stage 3 , the kernel grows, the hull separates from the shell, and the shell splits, right.

spring, however, can substantially increase the formation of early-split nuts, resulting in increased levels of moldy and insect-damaged nuts.

Therefore pistachio growers should be careful to provide sufficient irrigation during spring.

M.A. Doster is Staff Research Associate and T.J. Michailides is Professor, Department of Plant Pathology; D.A. Goldhamer is Water Management Specialist, Department of Land, Air and Water Resources; and D.P. Morgan is Staff Research Associate, Department of Plant Pathology, UC Davis, located at the Kearney Agricultural Center, Parlier. The authors thank L.D. Boeckler for her excellent technical assistance and the pistachio growers for their cooperation. This research was supported by U.S. Department of Agriculture Cooperative Research Agreement No. 58-53251-194.

\section{References}

Crane JC, Bradley MV, Nelson MM. 1971. Growth of seeded and seedless pistachio nuts. J Am Soc Hort Sci 96:78-80.

Doster MA, Michailides TJ. 1995. The relationship between date of hull splitting and decay of pistachio nuts by Aspergillus species. Plant Dis 79:766-9.

Goldhamer DA, Kjelgren RK, Williams L, Beede R. 1985. Water use requirements of pistachio trees and response to water stress. In: Proceedings of the National Conference on Advances in Evapotranspiration. St. Joseph, MO: American Society of Agricultural Engineers. p 216-23. 